\title{
Business Analysis of Automotive after-market under the Internet Background
}

\author{
DanniSong $^{a}$, RongZeng ${ }^{b}$ \\ Wuhan University of TechnologyHuaxia College, Wuhan430000, China; \\ asong@163.com, 'bengr@126.com \\ Keywords: Internet, Second-hand car, Consumer credit, Finance lease, Auto insurance.
}

\begin{abstract}
With the "Internet + Plan" proposed cross-border integration trends become more apparent. Under the guidance and the impact of big data, from automotive design and manufacturing to sales terminals, pre-service mode are faced with new challenges, there are also huge opportunities. Based on this background, the paper automotive after-market for the object, described a typical "Internet + Car" event, analysis of the automotive market in the Internet environment, the main business of commercial operation.
\end{abstract}

\section{Introduction}

2014 is an important period for the development of the Internet car market, domestic and foreign IT, Internet and car manufacturers, and other industries and enterprises have the layout of Internet automotive industry chain, the exposure of the rapid increase of Internet car from Tesla's domestic sales to Apple, Ali Baba joined the automotive industry, have shown that the Internet is an important area of automotive Internet era[1].

At the same time, car sales have exceeded 20 million, more than 130 million cars in 2014 . In the rapid development of the automotive industry but also to the automotive after-market has brought huge business opportunities, the automobile market is the industry chain, the most stable source of profit, data show that the car after-market overall industry profits can reach $40 \%-50 \%$ (Fig. 1 ) in some sub-sectors may even reach $100 \%-200 \%$ of the profits. At the same time, Internet-based collaboration automobile market more deeply, there were many in the Internet as a platform for business, the development of the automotive industry, the market has been heavy resource-based to service-oriented market changes.

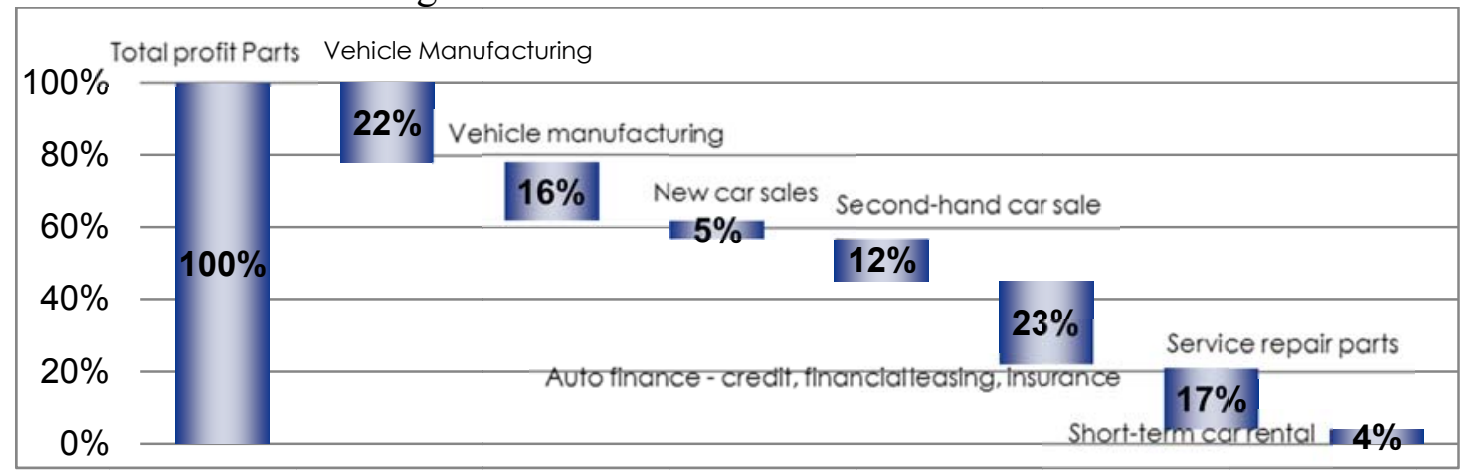

Fig.1 Profit Distribution of Mature automobile industry chain

Typical "Internet + car" Introduction. (1) Internet car. After the two sessions of 2015, the Ministry of software, information services Division held a "push automotive software development, to meet the smart car era," the theme of the seminar, "Internet + car" has entered the agenda of the Ministry of Industry, Internet companies have joined the automotive market, compare with a representative Alibaba.

Alibaba early as in September 2010 Mercedes-Benz Smart Start Taobao buy event, had set his sights on the automotive market, after five years penetrated into the automotive supplies, new car sales, map navigation, auto finance, used car and many other business segments. Signed the "Internet car" strategic cooperation with SAIC in 2014 agreement to cooperate in the "Internet car" and related applications service areas, work together to build the future "Internet car" and its ecosystem, notices it officially entered the automobile industry. 
(2) Telematics. Setting up a "Vehicle networking industry technology innovation strategic alliance" in August 2013 in Beijing, the Alliance members included car manufacturers, mobile operators, hardware manufacturers, software service providers and related research institutes and other 15 whole depot including a total of 30 units, the aim of promoting vehicle networking technology for automobile safety and economy and other performance applications.

Telematics refers to the network based on the car, the car interpersonal networks and mobile Internet-based vehicle, according to the communications protocols and data exchange standards agreed between cars and trucks, road, pedestrians and the Internet, wireless communications and information exchange Large system network, to achieve intelligent traffic management. Baidu announced the launch vehicle networking solutions CarLife in 2015, whereby the overall layout of the car networking fields. Baidu CarLife is a cross-platform vehicle networking solutions, in the car-side, whether it is Linux, QNX or Android, CarLife can be adapted; on the user side, CarLife can support Android and iOS smartphone operating system, able to cover 95\% more smartphone users. CarLife Users simply connect their phone to the vehicle system, use a variety of applications in the process of driving through a data cable or wifi.

(3) New energy vehicles. New energy vehicles refers to the use of unconventional vehicle fuel as a power source, power control and drive advanced technologies integrated vehicles, advanced technical principles formed, with new technology, new structure of the car.

Tesla electric car brand to enter the domestic market in 2014, the CES conference demonstrated the first SUV model-Model Xin January 2015, the main features include multimedia systems, navigation, 3G networks, voice telephony. Future, we expected that the domestic IT industry leader and music as millet layout Internet car market, with its excellent marketing and Internet thinking, will further enhance the awareness of the consumer market. In addition, Beijing Automotive and Audi, other auto manufacturers have indicated that the introduction of a new electric car in 2015, the iterative application of electric cars with mileage endurance, intelligence and other aspects.

(4) Super Car. Leshireleased as Super Cars "See" planning process, and released the first smart car UI system in 2015, the goal is by completely independent research and development to create intelligent Internet electric vehicles, electric cars achieve, intelligent, Internet-based. Music as the car will be completely subvert the existing automotive products, including R \& D, marketing model, business model, business model, etc., through the establishment of automotive Internet ecosystem, an effective solution to urban smog and traffic congestion, so that everyone can breathe pure driving a super car air.

Auto market business analysis. (1) Second-hand car. With the rapid development of China's second-hand car market, the Internet has penetrated into all aspects of the second-hand car trading, including second-hand car show, testing, evaluation, sale, payment, logistics and so on, second-hand car service provider's business model is also more mature, more Diversification.

Does not consider the second-hand carr business brand car sales companies carry out their own, in addition to the traditional buy-out service providers (such as An Meitusecond-hand car, Schumacher second-hand car), as well as information-oriented second-hand carinformation service providers (such as 51 vehicles, the first car network), the recent pattern has been found in a number of innovative service providers second-hand car, second-hand car online auctions such as excellent letter shoot, car easy to shoot, second-hand car trading services such as 273 , large search vehicles, the business model largely as a catalyst for innovation stage release of second-hand car market is huge market potential.

(2) Automobile consumption credit. In the car loans market, more than $80 \%$ share of the automotive finance companies and commercial banks to provide consumer credit and credit card business, but some car loan demand can't be met, which is a huge business opportunity for Internet banking. After the traditional automotive finance companies and commercial banks, finance companies are becoming Internet trillion of new forces have personal automobile consumption credit market.

Automobile consumption credit is mainly used in $\mathrm{P}$ to $\mathrm{P}$ mode, which is the typical format of Internet banking, but most of the existing car loan $\mathrm{P}$ to $\mathrm{P}$ platform automobile mortgage loans, high 
interest rates, high risk, high rate of bad debts; while insufficient assets side, small market size, specifically for consumer installment loans personal car is not much. Based on this problem, automobile credit companies will both automotive financial services, incorporating internet online financial trading platform, while increasing investment in the line, open at both ends of the supply and demand for direct transactions, improve capital utilization of both loans, at the same time select three or four tier cities and second-hand passenger vehicles installment loans started this business model due to the implementation of "small scattered wind control closed loop", reducing the risk of loans.

(3) Car financing and leasing business. The data show that the market scale of China's auto finance has exceeded 700 billion in 2014, the auto finance market size of $25 \%$ per year rate of sustained expansion, expansion of auto finance from continuing growth in new car sales, new car market this year, increasing slowing down the speed of environmental, automotive finance lease is regarded as an important way to drive automobile consumption growth.

Car finance lease, also known as "rents Shopping", is also seen as a way of installment purchase. Shopping can be implemented to rent separate car use and ownership, customers can first car after a car, to obtain long-term lease the right to use a vehicle from a dealer or leasing company's hands, the monthly rent payment. After the lease expires, the user can choose to buy or return the car to the car rental company in accordance with the residual value of the vehicle, the rental prices are generally much lower than for the month. July 2015, Alibaba teamed up numerous automobile manufacturers in the mobile phone Lynx, mobile phones and other mobile end Taobao to promote "car second loan" business, announced its entry into the auto finance. In September, Yi car company capital,a subsidiary of Xin Yi offers used car evaluation and other services to the owners, its shareholders include Jingdong, Tencent and easy car, a number of Internet companies is accelerating march to auto finance.

(4) Internet car insurance. Auto insurance business property insurance business has been the focus of fierce competition in the market is the insurance companies, and competition in the auto insurance business has shifted from competition to lower channel line Internet competition line. Internet auto insurance is the insurance industry, a big step forward for change, from the Internet to the insurance industry remodeling process, the Internet is just the beginning of auto insurance, auto insurance field next will occur disruptive change triggered an open platform.

Currently, the Internet and traditional insurance and auto insurance is no essential difference, the only difference is the lower line cumbersome for the process evaluation system and concentrated to an "information package" open to users, locate the product to the user changes from the original business users. Internet auto insurance is exactly the same kernel with traditional products, is still based on hardware-based indicators to assess the information which lag between assessment system and auto insurance product is asymmetric, and flat with the Internet, it does not match the immediate flow of information.

\section{Summary}

Internet penetration of the automobile market, not only in the second-hand car, consumer credit, financial leasing and auto insurance aspects, but also car maintenance, automobile e-commerce. Undoubtedly, the "Internet + car" will be the development direction of the automotive industry, and the market as the automotive industry chain profits after the major part of the car, it is the first to join and compete for business objectives, will also change its business model continue to occur. 


\section{Reference}

[1] Y. Zhen, J. Liu. Opportunities and challenges facing the automotive business in the Internet age. Managers, August 2015 